Journal of the American Medical Association.

EDITED FOR THE ASSOCIATION BY N. S. DAVIS.

PUBLISHED WEEKLY.

Vol. X. Chicago, MarCh IO, I888. No. IO.

ORIGINAL ARTICLES.

\author{
THE DIFFERENTIAL DIAGNOSIS OF UREMIA. \\ BY CHARLES W. PURDY, M.D., \\ OF CHICAGO. \\ HON. FELLOW OF ROYAL COLLEGE OF PHYSICIANS AND SURGEONS, \\ KINGSTON.
}

It will be my object in this paper to draw the line as sharply as possible between those comatose states which are sometimes mistaken for uræmia, and the latter condition itself. I am the more willing to undertake this task, believing that the importance of the subject can scarcely be overestimated. It is surely no uncommon experience with those who are engaged in active general practice to meet with cases in which men-especially those advanced in lifehave been suddenly struck down in an unconscious state to which, unfortunately, too often death constitutes the speedy sequel. Indeed, so frequently is this picture presented to the professional eye, that in the aged it has come to be looked upon almost as a matter of course. To the mind the thread of possibility, by which depends the lengthened skein of life, grows so brittle with advancing years that its individual strands seem scarcely worth the efforts at strengthening. And thus the tears of friends, and perhaps the qualms of the scientific conscience are soothed by the reflection that as the leaves turn yellow they must fall; so the aged must die.

In a given case of unconsciousness of sudden onset, the result may be speedy death or recovery, depending very much upon the cause and the measures employed for relief. And this.brings us at once to the importance of an accurate and speedy diagnosis in such cases.

A number of conditions accompanied by more or less complete unconsciousness are to be met with that may be confounded with uræmia. It is important that the symptoms and signs of these various states should receive the most careful consideration and study; for upon these we must often depend solely as data upon which to construct our diagnosis. The history and important facts bearing upon the case of course should not be lost sight of, since these frequently come to our aid opportunely in doubtful cases. Since, however, a state of unconsciousness precludes the possibility of gaining any definite oral information from the patient it becomes more necessary in these than in any other class of cases to be able to readily construct the diagnosis from the symptoms alone.

In order to differentiate accurately uræmic coma from the various conditions with which it is sometimes confounded I shall first endeavor to draw a correct picture of the various phases of uræmia itself; and passing from this I shall consider the various conditions with which it is more commonly confounded; and lastly, I shall present in tabular form the chief features of each, that the observer may at a glance study their differential features.

Without entering at present upon the much vexed question of the nature of the uræmic power itselfwhich still remains an unsettled problem-it should first be noticed that it usually expends its greatest force upon the nervous system, and therefore we must look to the nervous system for the most prominent manifestations of this disorder. So far as the central nervous system is concerned, it is a somewhat remarkable fact that the uræmic poison usually acts upon the sensory and motor centres in diametrically opposite ways. Upon the sensorium the tendency is towards abolition of function-and consequently tending to insensibility and coma; while upon the motor centre-the medulla-exaltation or stimulation is produced - tending towards convulsions. Coma and convulsions then are the most common results of the more intense action of the uræmic poison upon the central nervous system; but in less intense degree of action the uræmic poison often seems to reverse this order-on the sensorium to produce excitement, delirium, etc., and upon the motor centre to produce a mild and transient paralysis. This latter fact should not be lost sight of since in the first place it is perhaps not generally known that uræmic coma and convulsions are often preceded by paralysis; and in the second place the occurrence of paralysis may lead the physician to mistake uræmia for apoplexy-more than one such instance has come under my observation within the past year.

Uræmic coma is rarely of very sudden onset, but is preceded by certain well-marked symptoms for from a few hours to several days or even weeks. The most constant and prominent of these prodromata are, headache, nausea and vomiting, exalted reflex sensibility of the voluntary muscles, increasing drowsiness, more or less decided diminution of the volume of the urine, and a peculiar odor of the skin and breath-uræmic. Among the less common prodromata are, acute visual disorders, dyspnœe, distressing itching of the skin, restlessness by day and insomnia at 
night, delirium, deafness, paralysis, and convulsions.

The headache is most often frontal or temporal if the underlying cause be acute renal trouble; most often occipital if chronic-as cirrhosis or granular contracting kidney. Headache is perhaps the most constant of all the early symptoms of uræmia, and it is often very distressing. It may be distinguished from ordinary neuralgia by its non-conformance to the evening exacerbations so constant in the latter.

Nausea and vomiting are scarcely less constant symptoms, and when present are often very obstinate and prevent the successful administration of medicine by the stomach. The exaltation of reflex muscular sensibility is observed in the frequent twitchings of certain groups of muscles-most often those of the face. The visual disorder may consist of acute amaurosis - the patient becoming suddenly deprived of vision; or a more gradual and less complete impairment of vision may come on which is most likely to become permanent. The first form is more common in acute renal disease; while the second form is more common in chronic forms of kidney affections. The acute dyspnœa occurs in two forms-the first closely resembling asthma, and the second due to pulmonary œdema and characterized by rapid respiration, 40 per minute or more. A third form of respiratory disorder of not infrequent occurrence is Cheyne Stokes respiration - which should not be confounded with the more regular and uniform slowing down of the respiration due to large doses of opium.

Restlessness is often very marked and not unlike the condition preceding delirium tremens, save that the apprehensiveness of danger so marked in the latter is absent. The delirium-or mental intoxication -when present is peculiar in certain respects. Upon fixing the attention of the patient closely he is usually quite rational, and replies to questions intelligently; but he is usually very forgetful-often repeating a question he has just asked and received a reply to.

Insomnia is a prominent feature of the uræmic state; "these patients rarely sleep well" save under the influence of a narcotic.

Paralysis is most common in the muscles of the face-usually of one side-and often involving the tongue. It often extends to the arm and leg. Impairment of sensibility in the affected part is rarely complete even when the motor power is entirely abolished. The attack often lasts less than an hour and rarely does it continue longer than twenty-four hours.

Let it now be supposed that the physician is called to see a case of typical uræmic coma, in which state the patient has been accidentally discovered and a hasty diagnosis is demanded. The appearance of the patient is somewhat pallid. This pallor is not the result of weakness of the circulatory forces as in syncope, but is rather due to some underlying renal disease. It is therefore an unhealthy, partly cachectic pallor-familiar to those who see much of kidney disease. Exceptions to this rule (the appearance of pallor) occur chiefly in cases of early cirrhosis of the kidney when the color of the skin may not depart in the least from the usual tint of robust and perfect health.
Apparently the patient is profoundly insensible; in reality he is rarely completely so in pure uræmia. Upon vigorously shaking the patient, or shouting in his ear, indications are observable that consciousness is not entirely abolished. He may indeed very often be made to speak, or to reply to questions asked in a loud voice-though usually in monosyllables. If unable to do this there will at least be observable upon close inspection some expression of countenance indicative of perception, if not of comphension. Reflex sensibility of the voluntary muscles is still present and may be excited by percussion.

The pupils are somewhat dilated and the orbicularis responds to stimulants.

The breathing is often stertorous, but not deep and gutteral-the noise being made by the cheeks and lips not by the throat. The pulse is increased in frequency-90 to 120 per minute-is rather full, often hard and tense. The temperature is raised, marking $100^{\circ}$ to $102^{\circ} \mathrm{F}$. CEdema may or may not be present; if present it is more prominent about the malleoli and eyelids.

If the urine be drawn-and it always should be in doubtful cases-it will usually be found highly colored, and to contain albumin. The odor of the breath is characteristic-uræmic.

Such are the more trustworthy symptoms of uræmic coma, and they are essentially different from those of most other states of insensibility as will be presently seen.

If to these we are enabled to add the history of the case, we shall have many of the premonitory symptoms already considered as additional guides.

The condition most commonly confounded with uræmic coma is hæmorrhagic apoplexy: and since it is often the outgrowth of the same underlying cause as uræmia-vaso-renal change-it should receive most careful consideration.

In recent typical apoplexy the insensibility if present at all is usually complete-it being impossible to arouse the patient or to elicit evidences of perception or comprehension. This state may be reached gradually the same as in uræmia, though usually much more rapidly. The pupils may be contracted or dilated, and in this respect they are exceedingly variable. Inequality of the pupils-most common--is the more trustworthy sign. If the hæmorrhage occur in the pons varolii the pupils are contracted. The face may be pale but the general hue of the skin is usually normal. The respirations are increasingly stertorous and gutteral in character-the sound being made in the throat as in heavy deep snoring. The pulse is reduced in frequency, sometimes reaching 60 or even 50 beats per minute, and it is "labored." It is increased in volume and marked by tension. The temperature is usually subnormal, often marking $96^{\circ}$ F. Paralysis is usually present of the hemiplegic order. There are rarely true convulsions with apoplexy; the patient may fall and muscular spasms of a clonic order may follow, and even the tongue may be bitten, but it is not deeply lacerated as in epilepsy or in uræmia.

It should be remembered that in apoplexy several of the more important symptoms vary with the stage 
of the attack. Thus very early, the consciousness involving but the face or the face and arm. I have in may be preserved and insensibility may come on a few cases seen complete hemiplegia (motor). slowly. After a few hours the clot may and often does excite inflammation, thereby raising both the pulse and the temperature. Perhaps the most constant and valuable diagnostic symptom of apoplexy is hemiplegia. If actual paralysis cannot be made out definitely, a close scrutiny will yet nearly always reveal "one-sided symptoms" of some kind. If the arms be raised, for instance, and then permitted to drop, they do not fall uniformly.

Since apoplexy from cerebral hæmorrhage is confessedly the most difficult of all conditions to differentiate from uræmic coma, it is proper that they now be considered side by side, as it were, in a comparative sense. If the uræmic coma be the result of chronic Bright's disease its history is often identical with that of apoplexy. The patient is beyond middleage and well nourished. The left ventricle of the heart is more or less hypertrophied; indicated by heaving impulse of apex beat; accented second sound of the heart most distinct near and to the right of the sternum in the second interspace; also extended area of cardiac dulness. The arteries are hard-atheromatous-and the pulse is marked by decided increase in tension-well shown by the sphygmograph. Renal changes are almost as common in one case as in the other and, therefore, albuminuria will not form a safe distinguishing guide here. The premonitory symptoms are much alike in each case, viz. : vertigo, visual disorders, epistaxis, drowsiness, pain in the head, and vomiting. Indeed the very time of attack coincides, being most frequent after some unusually active or long continued exercise.

Generally speaking; the age of the patient is of service as an aid in distinguishing doubtful cases. Thus, apoplexy is almost limited to middle and advanced life. Albuminuria in the aged is for the most part due to contracting kidney-cirrhosis-and $\mathrm{my}$ own obervations have shown me that contracting kidney more often gives rise to convulsions without than with coma.

On the other hand if the patient be under 30 years of age, apoplexy would be improbable, and uræmia would, moreover, be less likely to be overlooked, since it would then as a rule depend upon an acute renal disease, the symptoms of which could scarcely escape observation.

Passing now to a more minute analysis of the chief symptoms of uræmia and apoplexy. It has already been stated that paralysis is the most constant and characteristic indication of apoplectic coma. Its chief features are its completeness, permanency and one-sided character-hemiplegic. It comes on before or with the loss of consciousness, and it lasts through the attack with little or no variation: and if the patient recover it is the last symptom to yield, cften in fact becoming permanent. Uræmic paralysis as a rule precedes the coma for some hours or days. It is transient, often lasting but half an hour, rarely longer than twelve to twenty-four hours, and consequently is rarely present during coma. While it is one-sided, it is rarely so extensive as in apoplexy

The pulse in apoplexy is slowed in the first stage, and usually does not become accelerated for many hours--until inflammation arises. In uræmia the pulse is accelerated from the first, before coma comes on, so that however early we meet with uræmic coma the pulse is increased in frequency-9o to 120 . The temperature follows much the same course in each. In apoplexy it is reduced in the first stage. It remains sub-normal for a variable time, always for hours, then it slowly rises, and in two or three days it may reach $100^{\circ}$ to ro $^{\circ} \mathrm{F}$.

In uræmia the temperature rises before coma comes on usually reaching to $100^{\circ}$ to $102^{\circ} \mathrm{F}$., and fluctuating between these points as the attack continues.

In convulsions due to uræmia the spasms are tonic, general, and usually repeated with more or less increasing frequency. As a rule the convulsions precede, and are several times repeated before the appearance of coma, the latter coming on slowly and gradually, hours usually elapsing before its full development. If unprotected, the tongue is bitten and often badly lacerated.

In apoplexy, as previously stated, true convulsions are rare; when present they are mostly clonic, rarely repeated, and precede the coma, the latter rapidly following the fall. The tongue may be bitten but is not deeply lacerated. In apoplexy the convulsions may be unilateral; in pure uræmia they are never so.

The loss of consciousness in apoplexy is more rapid, more profound, and less variable than in uræmia. An hour or so after the seizure, the patient is often completely comatose in apoplexy; and if he recover consciousness it most always requires several days for its accomplishment. In uræmia unconsciousness creeps on slowly in a fitful, vacillating manner; and even after apparently complete unconsciousness is reached, there maybe intervals of more or less consciousness until very late-near death. In uræmic coma I have rarely found complete abolition of perception save very near death, and there is pronounced irritability of the voluntary muscles upon percussion. In typical apoplectic coma abolition of consciousness is usually complete, and, moreover, when established the insensibility continues unchanged until death or general improvement occurs. In apoplexy the respirations at first are as a rule easy and natural. Sooner or later they become deepened, and finally stertor appears of a deep, noisy gutteral character. To one in an adjoining room the noise very much resembles loud snoring. In uræmia the respiratiors at first are also easy and natural. Should œdema of the lungs be present, however, which is not uncommonly the case, the respirations become rapid-40 to 50 per minute. Noisy stertor is rare in pure uræmic coma, and the little noise present is made with the cheeks and lips-a soft puffing noise. Gutteral stertor may appear near death; as it often does upon the approach of death from many causes other than uræmic.

If any information of value is to be gained from the pupils, it is mostly in the earlier stages of uræmia and apoplexy. In the former the tendency is to di- 
lation of the pupils; sometimes, indeed, they are so widely dilated as to give rise to suspicions of belladonna poisoning. In apoplexy the pupils are very variable. Sometimes one pupil is dilated and the other contracted, or one pupil may be normal and the other one either contracted or dilated. Inequality is the more common feature. It should not be forgotten that on the near approach of death from most causes, the pupils often become widely dilated.

Having now reviewed the chief differential features of uræmic and apoplectic coma, I shall next take up the subject of epilepsy, and note in passing the differential features of its symptoms from those of uræmia. First, as to the history. It will of course be unusual to meet with a first attack of epilepsy, and therefore it will be generally known by the friends that the patient is subject to "fits."

Epilepsy is a disease of the young- 75 per cent. of the first attacks occur before 20 years of age. The attacks are most common at night, unlike in both apoplexy and uræmia. The attack is always sudden, a few moments at most constituting the prodromal stage. Convulsions always precede the coma, and they are of the tonic order. Consciousness is completely abolished from the beginning; even before the convulsions begin. The convulsions are rarely repeated the same day, more often several days or weeks elapse before their return. In uræmia, it will be remembered, a few hours at most elapse between the convulsions when repeated. In epilepsy consciousness gradually returns after the convulsive attack, the average period of coma being about one hour, unless the attack occurs at night, when it is much longer. In uræmia unconsciousness does not usually occur until after several attacks of convulsions, and it gradually deepens instead of wearing away after the fits.

The coma following the epileptic convulsions is much like a sound sleep; after the first few minutes, as a rule, the patient can easily be aroused. There is rarely true paralysis and, when present, it is probably due to cerebral hæmorrhage. It is true there is nearly always more or less loss of power after an epileptic convulsion, and in the arms and limbs this may be apparently complete; but it wears away in a few minutes or hours, being a weakness or prostration rather than a paralysis. The coma of epilepsy is most often a confused mental state from which the patient may be easily aroused. There is usually un. steady stertor, "coming and going," guttural in tone, and the unconsciousness varies greatly both in intensity and in duration. In epileptic coma reflexes are not abolished; the pupils are normal, the conjunctiva is sensitive, and the orbicularis responds. The skin is usually bathed in perspiration-at first warm, dusky and purple, but gradually cooling and becoming pale.

The temperature does not vary much from normal; perhaps a rise of half a degree may be noted. If, however, the convulsions be rapidly repated, the temperature may rise above $100^{\circ} \mathrm{F}$.

The pulse in epileptic coma is rather small and feeble, though regular, and it may be slightly increased in frequency. If a tracing be taken with the sphygmograph it shows the features of dicrotism. It will be seen from the foregoing description that epilepsy does not closely resemble uræmia, save in the convulsive seizures, and these are strikingly similar, except in their frequency of repetition. Practically, it is only those cases of epilepsy in which the convulsions are rapidly repeated, and the coma consequently deep and prolonged, that are likely to be confounded with uræmia. Happily, such attacks are rare, and for the most part due to traumatic causes which rarely escape attention.

We have next to consider the coma depending upon alcoholism, often one of the most difficult conditions to diagnosticate. There are, indeed, few states of unconsciousness with which it may not be confounded. Drunken stupor has even been mistaken for syncope and, strangely enough, the unfortunate patient has been made to swallow brandy for the purpose of reviving him. The coma of drunkenness varies in intensity according to the dose of alcohol taken, and the susceptibility of the patient to its influence. There may be only quiet stupor, from which it is easy to arouse the perceptive and volitional powers of the patient; or all the senses may be abolished, the patient being completely unconscious, stertorous, comatose and anæsthetic.

In typical drunkenness the breath is usually loaded with alcohol, and this is readily recognizable by the odor. It is especially so if the debauch be due to spirits. The odor of alcohol in the breath, while it is a strong presumption of drunkenness, yet must not be absolutely relied upon as the cause of unconsciousness, since epilepsy or apoplexy sometimes supervenes upon a fit of alcoholism.

The respirations are heavy and often stertorous in drunkenness. The stertor, when present, is variable and intermittent. The respirations are deep-drawn and less frequent than normal. The stertor is similar to that of heavy sleep. The expression of countenance is vacant; sometimes the features are suffused and bloated; the lips are livid; the pupils are dilated, and the conjunctiva is much injected.

The pulse is small and rapid, and the heart's action is feeble. The temperature is usually subnormal. The skin is usually covered with cold, clammy perspiration. Vomiting is common, and evidences thereof should be sought for about the mouth or clothing. In some cases it is possible to arouse the patient to some degree of consciousness by shaking or pinching him. He may be made to speak, to give his name and address, and if so it is to be noticed that the articulation is thick, drawling and indistinct. He awakens confusedly and relapses again into apparent sleep. Sometimes, however, the patient becomes irritable upon disturbance and indulges in swearing. This is often the diagnostic sign relied upon by the police patrolman, who seeks to elicit it by sharply striking the sole of the shoe with his baton; an excellent means of exciting reflexes, but an untrustworthy diagnostic of alcoholism, since patients in apoplectic conditions will sometimes resent such disturbance both verbally and muscularly. It has been stated that if the patient be aroused sufficiently to be able to speak, the articulation is thick and indistinct. This indicates a disproportionate action 
of alcohol upon different centres of the nervous system, which is often very marked.

Tactile sense and motion are usually in reality more disturbed than is cerebral perception and consciousness. In other words, coördination of muscular action and special sense are more impeded than is cerebration. The patient often reasons so well with himself that he requires to be told that he is drunk, unless he attempts to walk, when difficult coördination of muscular motion teaches him that he is intoxicated. The medulla and spinal cord, therefore, are more deeply anæsthetized than is the cerebrum. In certain individuals these features of alcoholism are especially prominent; indeed, in such the intellectual faculties are actually sharpened, even when motor coördination is greatly impaired. In such cases most brilliant reasoning powers are manifested or able speeches delivered even though the subject be unable to stand without support. It will be remembered that, in describing uræmia, it was stated that the uræmic poison tended to a directly opposite action upon the central nervous system, viz.: to stimulate the spinal system and medulla, and to depress the cerebral centres. If, therefore, the patient can be in a measure roused, these distinguishing features should be carefully observed in all doubtful cases.

Dr. von Wedekind has recently brought forward ${ }^{1}$ a new test of drunkenness for which he claims "infallibility." "By simply pressing on the supraorbital notches with a steadily increasing force you may, with certainty of success, bring an unconscious alcoholic to his senses, and thus differentiate on the spot between alcoholic and other comas." Incredible as this may at first sight seem, Dr. von Wedekind has brought forward a record of 137 cases of alcoholic coma gathered from the ambulance service in which his test has been applied, and in the nine cases of failure of the test out of the whole 137 , each one was accounted for by subsequent discovery of some additional cause of the coma.

From what has been already stated as to the action of alcohol upon the central nervous system, it would be expected that convulsions would be rare from this cause, and such in fact is the case. A single convulsion does sometimes occur during, or more frequently preceding alcoholic coma, but rarely are convulsions repeated in pure alcoholism as in epilepsy or in uræmia.

It seems necessary, in passing, only to mention the possibility of confounding syncope or hysteria with uræmic coma. These affections are so familiar to those in general practice, and the symptoms are so well known, that they are not likely to be mistaken for any of the states already considered. In syncope especially the unconsciousness is so brief, and the return to consciousness is so complete, that nature soon reveals the diagnosis; while in hysteria the symptoms, though exceedingly variable, yet possess a general definiteness familiar to all. It remains, therefore, but to consider the subject of poisoning as contrasted with uræmic coma. Although various narcotics produce a state of insensibility and coma,

\footnotetext{
${ }^{1}$ N. Y. Medical Record, August 27, 1887.
}

as well as death in large doses, the effects of opium alone will be considered here, since it is the narcotic for the most part selected for destructive purposes, as well as the one, from its wide range of use, which most commonly gives rise to accidents.

The physiological action of opium and its preparations upon the human organism in medicinal doses is well known. It is only with the larger doses-approaching lethal-that we now have to do; since it is only the deep narcotism induced by decided doses that constitutes the coma likely to be confounded with uræmia.

In coma due to opium the patient may be aroused sometimes to a greater or less extent, but quickly lapses into stupor. In late stages it is difficult, if not impossible, to rouse the patient. The pupils are minutely contracted and insensible to stimulation. The respirations become slower and more shallow, generally feeble, and sometimes stertorous. They may become reduced to ro per minute or under. The frequency of the respirations is perhaps the best gauge of danger, since in most cases of death from opium the direct cause is asphyxia from paralysis of the respiratory centres. The odor of opium is usually present in the breath. The pulse is slow and feeble; the face is shrunken, pallid, cyanosed, and the expression is ghastly. The eyes are heavy and the lips are livid. The skin is warm and moist with perspiration, and often intensely itching, especially about the nose.

In differentiating the coma of opium from that due to other causes, the special features to be noted are, first, the contracted state of the pupils. This is almost pathognomonic, and is only absent at the approach of death. Hæmorrhage into the pons Varolii, as first pointed out by Wilks, induces a similar contraction of the pupils; but this is almost the sole morbid state that produces the uniform and extreme contraction of the pupils similar to opium narcotism. Second, the slowing down of the respirations is almost characteristic of opium coma. It is to be borne in mind that, in the early stage of opium narcosis, the respirations are rather hastened; eventually, however, if the dose be large, the respirations become decidedly less frequent. Cheyne-Stokes' respiration, which is very common in uræmic states, should not be mistaken for retarded respirations due to opium. The distinction is easy, and it is only necessary to mention the possibility of mistake to guard against it.

Convulsions are rare from opium. In many of the lower animals the action of opium constantly tends to produce convulsions, but in man this result is chiefly confined to children. The history is important mostly in an exclusive way-the symptoms of the states already considered, as a rule, being absent. Aside from this, opium poisoning is most frequent in the young.

It should be borne in mind that, in the consideration of the various states of unconsciousness described in this paper, the aim has been to depict the more trustworthy features of typical cases. Variations from these types are to be met with, even in uncomplicated cases, which tax the skill of the most acute diagnostician. 
DIFFERENTIAL TABLE.

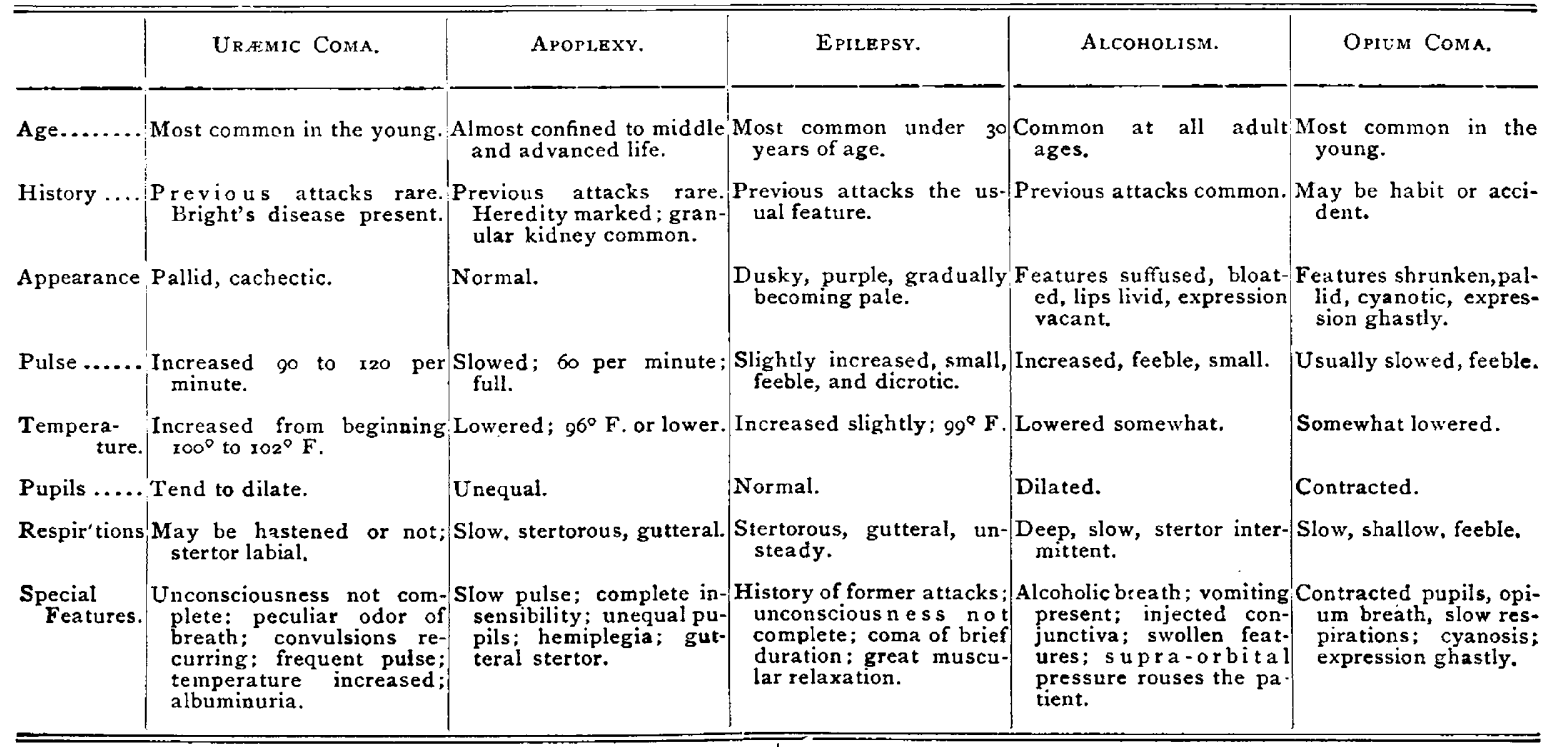

It should likewise be remembered that two, or even three of the causes considered may combine to produce a given state of insensibility, thus bringing about considerable confusion of the symptoms. Thus, a patient the subject of granular kidney-interstitial nephritis-may take a dose of opium, the tendency of which will be to suppress the urine, and uræmia may be the result. Furthermore, repeated uræmic convulsions may induce cerebral hæmorrhage, since all the conditions are favorable to such result in patients with granular kidneys. In such a case we have the symptoms of apoplexy added to those of uræmia, which latter, in turn, arose from the effects upon the kidneys of the opium. Again, the ingestion of a large dose of alcohol may precipitate an attack of convulsions in an epileptic subject, and in turn the convulsion may lead to cerebral hæmorrhage. The possibility of mixed cases should therefore be kept in mind. Happily, such cases are comparatively uncommon, but when they do occur they are only to be detected by careful study of the leadiug symptoms of each stage of the attack, since one cause usually supervenes upon another, rather than all occurring simultaneously.

In conclusion, it is hoped that the appended differential table may aid the diagnostician by presenting at a glance the leading features of each of the comatose states considered in this paper.

$16_{3}$ State St., February 27, 1888.

\section{GUNSHOT WOUNDS OF THE ABDOMEN.}

Read before the Chicago Pathological Society Feb. 13, 1888. BY J. B. MURPHY, M.D.,

OF CHICAGo. SURGEON TO COOK COUNTY hospital.

Case 1.-H. M., age 26, admitted to the hospital at 8 P.M., June 16 , 1886, suffering from a bullet wound of abdomen. I saw him at ro P.M. He was suffering but little from shock; pulse 9o; temperature normal; no pain. On examination, I found a large bullet wound half an inch below umbilicus, and an inch to the right of median line. I decided to make laparotomy, and assisted by Dr. E. W. Lee, and the House Staff of the Hospital, I made the median incision three and one-half inches long. I began by examining the small intestine and repairing each wound as it was exposed by first paring off the ragged edges with a scissors, then inserting a continuous catgut suture in the mucous membrane, then in the peritoneal covering, the first row of sutures being entirely covered by the second. This was continued until the eleven openings were united. I found that the bullet had passed through the posterior peritoneal wall close to the pelvis of left kidney; cleansed the peritoneal cavity with a warm $1 / 2$ per cent. carbolized water, united the abdominal peritoneum behind with catgut, also the opening made in the anterior peritoneal wall by the bullet, sewed the peritoneum at the incision with a continuous catgut suture, the muscular wall with deep silk suture (interrupted), dressed the parts with iodoform gauze, then carbolated gauze and borated cotton. Operation lasted two hours; patient's condition good after the operation was completed; pulse Iro, and of good volume.

The following morning the House Surgeon reports : "No vomiting, patient slept the greater part of the night, did not complain of pain; pulse I Io; temperature $991 / 2^{\circ} \mathrm{F}$; no thirst or tympanites. At 7 P.M. pulse 96 ; temperature $99^{\circ}$ F. No vomiting and no pain; says he is hungry." I called at the hospital the following morning and found that the patient had died suddenly at 7:30 A.M., after spending a quiet and painless night. At 6 A.M. he complained of weakness and said he was fainting

Autopsy.-Found heart and lungs normal; abdomen filled with blood. The suture in post-peritoneal wall torn through, a large quantity of blood in 